\title{
Preparation of Magnetic Paper from Kenaf: Lumen Loading and in situ Synthesis Method
}

\author{
${ }^{1}$ C.H. Chia, ${ }^{1}$ S. Zakaria, S. Ahamd, M. Abdullah and ${ }^{2}$ S. Mohd. Jani \\ ${ }^{1}$ School of Applied Physics, Faculty of Science and Technology \\ Universiti Kebangsaan Malaysia, 43600 Bangi, Selangor Darul Ehsan, Malaysia \\ ${ }^{2}$ Forest Research Institute Malaysia (FRIM) Kepong, 52109 Kuala Lumpur, Malaysia
}

\begin{abstract}
Magnetic papers have been successfully prepared from unbleached kenaf (hibiscus cannabinus) kraft pulps via the lumen loading and in situ synthesis process. The lumen loading method allows the magnetic fillers to be introduced into the lumen of fibres and at the same time leaving the external surfaces free from filler, resulting the better inter-fibre bonding and subsequently its papermaking properties are not affected. Fillers, which deposited in the lumen of fibres will be protected from further mechanical influences. For the lumen loading process, commercial magnetite $\left(\mathrm{Fe}_{3} \mathrm{O}_{4}\right)$ powders have been introduced into the lumen by mixing the pulp and magnetic powder. For the in situ synthesis process, nanosized magnetite particles have been precipitated in the presence of pulp fibres and deposited inside the lumen of fibres via chemical coprecipitation process. The samples were characterized by X-ray diffraction (XRD) and scanning electron microscopy (SEM) and their magnetization properties were examined by a vibrating sample magnetometer (VSM). The loading degree of the papers was estimated by using the Thermogravimetric analyzer (TGA). The VSM results show that the magnetic properties of the lumen loaded papers are higher compared to the in situ synthesis papers in which can be explained that the nanosized magnetite particles possess superparamagnetic properties. However, the SEM micrograph shows that the size and the distribution of the magnetic particles inside the lumen for the in situ synthesis papers are much better than that of the lumen loading papers.
\end{abstract}

Key words: Magnetic paper, lumen loading, in situ synthesis, magnetite, ferrite synthesis

\section{INTRODUCTION}

Magnetic paper can be obtained via lumen loaded fibres or synthesizing ferrite in situ. Magnetic properties are an additional value to the traditional paper which offered an exploration of new concepts in papermaking, information storage, security paper, paper handling, paper sensing and electromagnetic shielding ${ }^{[1]}$. For the lumen loading technology, filler particles either magnetite $\left(\mathrm{Fe}_{3} \mathrm{O}_{4}\right)$ or maghemite $\left(\gamma-\mathrm{Fe}_{2} \mathrm{O}_{3}\right)$ were introduced exclusively into the lumen of the fibres and leaving the external surface of fibre free from filler. The fillers are thus protected by the cell wall which do not hinder the interfibre bonding and subsequently diminish the loss of mechanical strength of paper. Cationic polyelectrolytes such as PEI, has been reported as an excellent retention aid to improve the filler retention inside the lumen of fibres ${ }^{[2,3]}$. Magnetic fibres may also be obtained by in situ synthesis, which allows a better control on the magnetic properties of paper by varying the divalent metal ion such as $\mathrm{Co}, \mathrm{Fe}, \mathrm{Mn}$ and $\mathrm{Ni}$, smaller particle size, better dispersion and greater uniformity ${ }^{[4,5]}$. Magnetic particles in the range of nanosized can be produced and thereby explore a new level of optical and magnetic properties. Iron oxide particles were performed via careful oxidation of ferrous hydroxide precipitated from the ferrous ion-exchanged form of sodium carboxymethyl cellulose fibres and the magnetic fibres containing small ferrite $\left(\mathrm{Fe}_{3} \mathrm{O}_{4}\right)$ particles about $10 \mathrm{~nm}$ in size $\mathrm{e}^{[1,6-9]}$. In the present work, however, the magnetic fibres were produced via the in situ synthesis of chemical coprecipitation technique by adding ferric $\left(\mathrm{Fe}^{3+}\right)$ and ferrous $\left(\mathrm{Fe}^{2+}\right)$ salts into the alkali solution under non oxidizing environment. This is the most common synthetic route to obtain magnetite particle compare with others, such as oxidation of $\mathrm{Fe}^{2+[10]}$ sol-gel method ${ }^{[11]}$ and water-in-oil microemulsions ${ }^{[12]}$, in virtue of its simplicity and productivity ${ }^{[13-16]}$. The reaction involved in this process can be represented as below:

$$
\mathrm{FeCl}_{2} \bullet 4 \mathrm{H}_{2} \mathrm{O}+2 \mathrm{FeCl}_{3}+8 \mathrm{NaOH} \rightarrow \mathrm{Fe}_{3} \mathrm{O}_{4}+8 \mathrm{NaCl}+8 \mathrm{H}_{2} \mathrm{O}
$$

\section{MATERIALS AND METHODS}

Lumen loading process: $30 \mathrm{~g}$ of magnetic pigment $\left(\mathrm{Fe}_{3} \mathrm{O}_{4}\right)$ was dispersed in $250 \mathrm{~mL}$ of distilled water which contained $0.1 \mathrm{~g} \mathrm{~L}^{-1}$ of aluminium sulphate for filler suspension with a laboratory mechanical stirrer. $15 \mathrm{~g}$ dry weight of unbleached kenaf pulp (hibiscus cannabinus) was disintegrated in $1250 \mathrm{~mL}$ of distilled water containing $0.1 \mathrm{~g} \mathrm{~L}^{-1}$ for $30 \mathrm{~min}$ in another

Corresponding Author: C.H. Chia, School of Applied Physics, Faculty of Science and Technology, Universiti Kebangsaan Malaysia, 43600 Bangi, Selangor Darul Ehsan, Malaysia 
laboratory mechanical stirrer at the rotor speed of 1000 $\mathrm{rpm}$. Later, the filler suspension was mixed with the pulp suspension and the mixture was stirred at the rotor speed of $1000 \mathrm{rpm}$ for $30-60 \mathrm{~min}$, forcing the particles to enter the lumen of fibres. This is called the impregnation stage. Then, the polyethylenimine (PEI,2\%,w/w polymer on pulp) as a retention aid was added and the suspension was then slowly stirred (400 $\mathrm{rpm}$ ) for $4 \mathrm{~h}$. Following the treatment stage, the excess pigment remained on the fibre surface and in the suspension was removed by washing with tap water in a self-designed fibre classifier containing a filter screen (45 $\mu \mathrm{m}$ ) for approximately $60-120 \mathrm{~min}$. The pulp was then used to produce magnetic paper.

in situ synthesis: Magnetite nanoparticles were produced by chemical coprecipitation with stoichiometric ratio $\mathrm{Fe}^{3+} / \mathrm{Fe}^{2+}=2$ and the addition of alkali. The reaction must be carried out under an anaerobic condition where the nitrogen gas flowed continuously through the solution purposely to degassed the solution and prevent oxidation of $\mathrm{Fe}^{2+} .15$ $\mathrm{g}$ dry weight of unbleached kenaf pulp was disintegrated in $1.5 \mathrm{~L}$ of distilled water for $30 \mathrm{~min}$ at the rotor speed of $3000 \mathrm{rpm}$ with laboratory mechanical stirrer to ensure the pulp was fully dispersed in the suspension. The suspension was then poured into the 3 neck, round-bottom flask with a mechanical laboratory stirrer at the rotor speed of $1000 \mathrm{rpm}$ and nitrogen gas kept passing through the suspension all the time for degassed the solution. The suspension was then heated to $60{ }^{\circ} \mathrm{C}$. Later, a stoichiometric ratio $1: 2$ ferrous chloride $\left(\mathrm{FeCl}_{2} \bullet 4 \mathrm{H}_{2} \mathrm{O}\right)$ and ferric chloride $\left(\mathrm{FeCl}_{3}\right)$ were added into the suspension immediately after weighing since $\mathrm{Fe}^{2+}$ and $\mathrm{Fe}^{3+}$ salts are oxidatively unstable. The suspension was then kept stirring for around 5 min to allow $\mathrm{Fe}^{2+}$ and $\mathrm{Fe}^{3+}$ salts homogenously dissolved into the pulp suspension. Sodium hydroxide $(\mathrm{NaOH})$ was then added into the suspension which immediately turned the suspension into black color, indicating the formation of magnetite. After $15 \mathrm{~min}$, polyethylenimine, PEI $(2 \%, \mathrm{w} / \mathrm{w}$ polymer on pulp) was added into the mixture as a steric stabilizer for magnetite nanoparticles and cationic polyelectrolyte for paper formation. The suspension was allowed to stir under the nitrogen atmosphere approximately 1 hour for the nucleation and growth of magnetite particles in the lumen of fibre. At the same time, vigorous stirring condition forcing the magnetic particles formed in the suspension to enter into the lumen of fibres, when the diameter was lower than the dimension of pits which distributed along the fibre wall. Like the lumen loading process, the excess particles remaining in the suspension and on the external surface of fibres are removed by washing and the pulp was used to produce magnetic paper.
Magnetic measurement: The vibrating sample magnetometer (LDJ 9500) has been used to measure the magnetization and coercive force of the samples at room temperature. The sample placed at the holder was vibrated vertically and the magnetic dipole of the sample induces an AC signal in a pair of coil.

Scanning electron microscope: The lumen loaded and in situ synthesized pulp samples were analyzed by using Leo 1450 VP model Scanning electron microscope (SEM). The papers were cross cut to observe the deposition of particles in the lumen of fibre.

X-ray diffraction measurement: The magnetic papers produced via the in situ synthesis method were then characterized by XRD using Siemens diffractometer D5000 with $\mathrm{Cu} \mathrm{K}$ radiation $(\lambda=1.5418 \AA)$ in the $2 \theta$ range of $25-70^{\circ}$. XRD is essential for identification and purity of the sample.

Thermogravimetric analyzer: The magnetic loading degree of the paper was estimated on a Pyris 1 Thermogravimetric analyzer by heating the sample (6-8 $\mathrm{mg}$ ) from room temperature to $900{ }^{\circ} \mathrm{C}$ with nitrogen purging at heating rate of $20^{\circ} \mathrm{C} \mathrm{min}{ }^{-1}$. The zero setting of the sample was started once the sample temperature reached $100{ }^{\circ} \mathrm{C}$ to ignore the moisture content of the sample. An empty sample (untreated) has also been tested in order to make the correction of the ash content to determine the loading degree of the treated samples.

Loading degree of paper $=\%$ Weight of treated paper $\%$ weight of empty paper

\section{RESULTS AND DISCUSSION}

Figure 1 shows the scanning electron micrographs of the samples obtained from lumen loading and in situ synthesis. As can be seen in Fig. 1, the size of magnetite particles in the in situ synthesis sample were extremely smaller than that in lumen loading sample. Magnetite $\left(\mathrm{Fe}_{3} \mathrm{O}_{4}\right)$ particles fabricated by chemical coprecipitation technique were in nanometer size $(\sim 60$ $80 \mathrm{~nm}$ ), whereas, the commercial magnetite pigments for lumen loading process were in micron size $(\sim 1-2$ $\mu \mathrm{m})$, as shown in Fig 1. However, the size and distribution of the magnetic particles in the lumen of fibres was more even for the in situ synthesis sample. In the in situ synthesis method, magnetite particles were formed on the spot inside the lumen of fibres once $\mathrm{NaOH}$ was added. During the initial stage, the $\mathrm{Fe}^{2+}$ and $\mathrm{Fe}^{3+}$ salts were dissolved and penetrated homogenously in the suspension and as well as inside the lumen of fibre by vigorous stirring with mechanical stirrer, thus leading to the better particle distribution. 


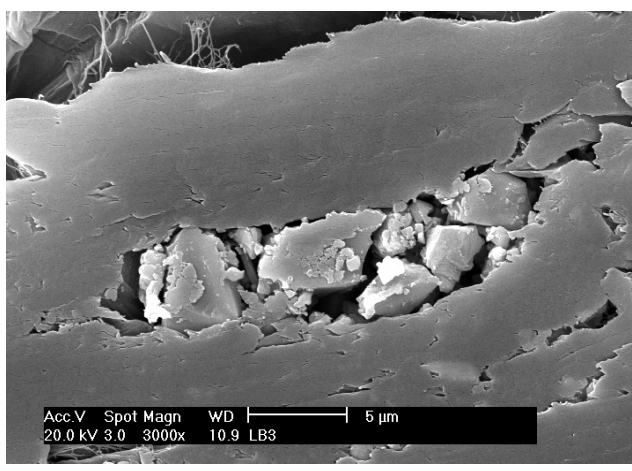

(a)

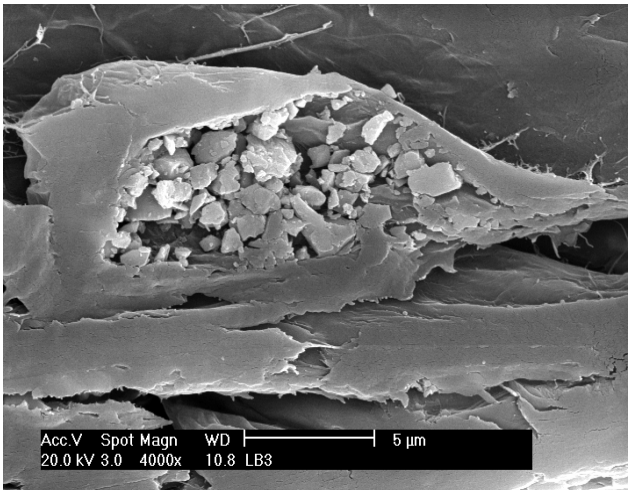

(b)

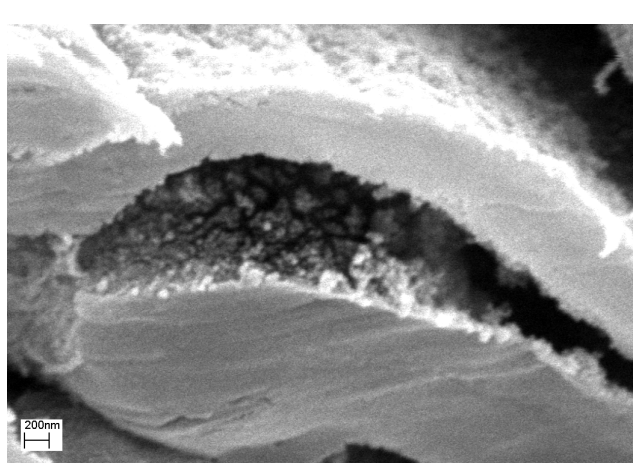

(c)

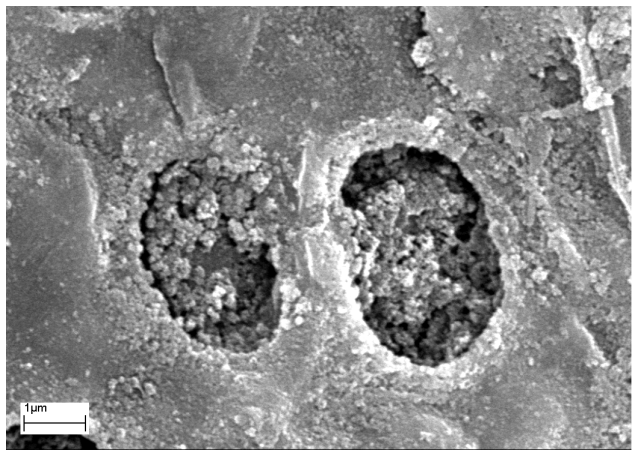

(d)

Fig. 1:Scanning electron micrographs of magnetic fibres, (lumen loading, A\&B; in situ synthesis magnetite, $C \& D$ ), showing magnetic particles were loaded in the lumen

Besides this, the huge surface energy of the magnetic nanoparticles as a result of its finite size leading them to be readily attached between each other
Table 1: TGA data of empty, lumen loaded and in situ synthesized paper

\begin{tabular}{lll}
\hline Sample & $\begin{array}{l}\text { Final sample } \\
\text { weight at } \\
900^{\circ} \mathrm{C}(\%)\end{array}$ & $\begin{array}{l}\text { Loading degree } \\
(\% \text { Weight of treated } \\
\text { paper }-\% \text { weight of } \\
\text { empty paper })\end{array}$ \\
\hline Empty & 7.179 & - \\
Lumen loading & 28.69 & 21.511 \\
in situ synthesis & 38.99 & 31.811 \\
\hline
\end{tabular}

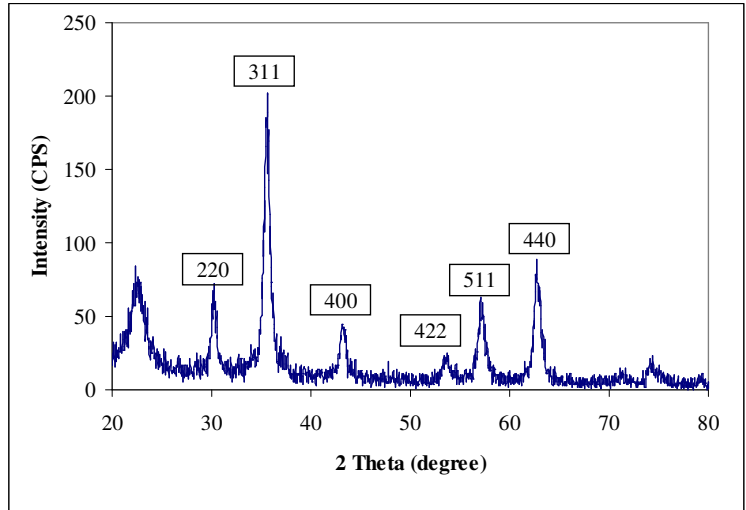

Fig. 2: XRD diffraction pattern of the in situ synthesized magnetic paper

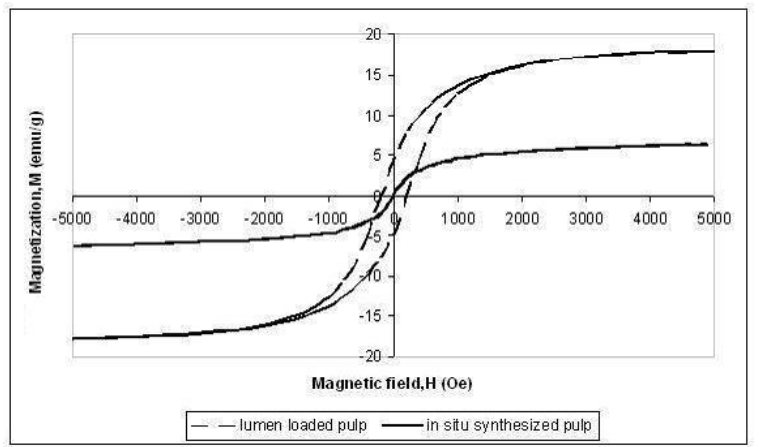

Fig. 3: Hysteresis loops of the lumen loading and in situ synthesis paper

and also onto the cell wall of the lumen. For the lumen loading process, commercial magnetic particles in micron size can only penetrate into the lumen of fibres if they have diameters smaller than the dimensions of pits $^{[2,5]}$. Furthermore, the diffusion of particles from the suspension into the lumen of fibres during lumen loading process can be easily affected by various factors, such as flocculation of particles into bigger size aggregates which may cause the difficulty to enter to the lumen of fibre ${ }^{[3]}$. Thus, the particles were less evenly distributed in the lumen of fibres. Besides this, the particle size of the commercial magnetite pigments was not homogenous as compare with in situ synthesized magnetic nanoparticles. This will affect the retention of particles on the fibres, because bigger sized particles are easier to detach due to their lower surface 
energy during the turbulence condition of the washing and papermaking process. Smaller size particles (nm) with vast surface area to volume ratio possess higher surface energy and they are thermodynamically unstable and tend to agglomerate and attach to one and other to reduce the overall surface energy ${ }^{[17]}$. Hence, the attachment of smaller size particles (nm) was stronger than the bigger size particles $(\mu \mathrm{m})$. The particles in different size attached weakly with one and other as well as on the fibres due to their different surface energy and subsequently easier to detach from fibres. It can also be proved from the TGA data shown in Table 1, where the loading degree of the lumen loading sample was lower than the in situ synthesis sample.

Figure 2 shows the XRD diffraction pattern of the magnetic paper produced via in situ synthesis method. The reflection peaks show that magnetite $\left(\mathrm{Fe}_{3} \mathrm{O}_{4}\right)$ was successfully precipitated on the fibres and no peak for impurities are detected.

The hysteresis loops for magnetic pulps are shown in Fig. 3. The sample derived from in situ synthesis exhibits saturation magnetization $(M s)$ of $6.339 \mathrm{emu} \mathrm{g}^{-1}$, which is lower than the sample obtained from lumen loading method (17.97 emu $\left.\mathrm{g}^{-1}\right)$. Besides this, the coercivity $(H c)$ of sample obtained from in situ synthesis is $13.63 \mathrm{Oe}$, which is much lower than the sample of lumen loading process (199.5 Oe). The lower magnetic properties of $M s$ and $H c$ for in situ synthesis paper basically are due to the nano-sized of magnetite particles. The smaller the particle size, the lower the $M s$ and $H c$. This is because of nano-sized magnetic particles possess superparamagnetic behavior. However, it can be improved by replacing the divalent metal $\mathrm{Fe}$ with Co or Mn.

\section{CONCLUSION}

Both lumen loading and in situ synthesis methods have been used in preparing magnetic papers. The XRD diffraction patterns show that magnetite $\left(\mathrm{Fe}_{3} \mathrm{O}_{4}\right)$ nanoparticles have been precipitated onto the fibres. Papers obtained via lumen loading process possess higher magnetic properties compare to in situ synthesis method. This is due to its finite (nm) size of particles synthesized by using chemical coprecipitation method, which shows superparamagnetic behavior. However, the size and distribution of magnetic particles of in situ synthesized paper are more homogenous and evenly distributed as compare with lumen loaded paper. in situ synthesis process was simpler and easier to control since the magnetic particles were formed directly in the lumen of fibre, as compare to the lumen loading method which required the diffusion of particles from the suspension into the fibre lumen. This can be proved by the higher loading degree of the paper of in situ synthesis than the lumen loading method. The non uniform size of commercial magnetic particles may contribute to the lower loading degree as compare with the in situ synthesized magnetic nanoparticles due to its low surface energy. Finite size particles are tended to aggregate and attach strongly between each other in order to minimize their surface energy and resulting the low detachment rate during the washing and papermaking process.

\section{ACKNOWLEDGEMENT}

This work was supported by IRPA grant 09-02-0210055 EAR (Malaysia). The author would like to thank to Universiti Kebangsaan Malaysia and FRIM (Forest Research Institute of Malaysia) for the pulping and testing facilities.

\section{REFERENCES}

1. Marchessaultt, R.H., P. Rioux and L. Raymond, 1992. Magnetic cellulose fibres and paper: Preparation, processing and properties. Polymer, 33: 4024-4028.

2. Zakaria, S., B.H. Ong, S.H. Ahmad, M. Abdullaha and T. Yamauchi, 2005. Preparation of lumenloaded kenaf pulp with magnetite $\left(\mathrm{Fe}_{3} \mathrm{O}_{4}\right)$. Mater. Chem. Phys., 89: 216-220.

3. Zakaria, S., B.H. Ong and T.G.M. van de Ven, 2004. Lumen loading magnetic paper I: flocculation. Colloids Surf. A: Physicochem. Eng. Aspects, 251: 1-4.

4. Garcia, J.A.C., N.A.L. Quintera and J.R. Rey, 1997. Characterization of ferrite particles synthesized in presence of cellulose fibers. Colloids Surf. A: Physiochem. Eng. Aspects, 121: 61-66.

5. Garcia, J.A.C., N.A.L. Quintera and J.R. Rey, 1995. Ferrimagnetic paper obtained by in situ synthesis of substituted ferrites. IEEE Trans. Magn., 31: 3126-3130.

6. Raymond, L., J.F. Revol and R.H. Marchessault, 1995. In situ synthesis of ferrites in ionic and neutral gels. Polymer, 36: 5035-5043.

7. Raymond, L., J.F. Revol, D.H. Ryan and R.H. Marchessault, 1994. In situ synthesis of ferrites in cellulose. J. Am. Chem. Soc., 6: 249-255.

8. Ricard. S. and R. H. Marchessault, 1990. Preparation of in situ magnetically loaded cellulose fibers. Mat. Res. Symp. Proc., 197: 319-324.

9. Marchessault, R.H., S. Ricard and P. Rioux, 1992. In situ synthesis of ferrite in lignocellulosics. Carbohyd. Res., 224: 133-139. 
10. Gokon, N., A. Shimada, H. Kaneko, Y. Tamaura, K. Ito and T. Ohara, 2002. Magnetic coagulation and reaction rate for the aqueous ferrite formation reaction. J. Magn. Magn. Mater., 238: 47-55.

11. Itoh, H. and T. Sugimoto, 2003. Systematic control of size, shape, structure and magnetic properties of uniform magnetite and maghemite particles. J. Colloid Interface Sci., 256: 283-295.

12. Lee, K.M. and C.M. Sorensen, 1992. Synthesis and characterization of stable colloidal $\mathrm{Fe}_{3} \mathrm{O}_{4}$ particles in water-in-oil microemulsions. IEEE Trans. Mag., 28: 3180-3182.

13. Wu, K.T., P.C. Kuo, Y. D. Yao and E.H. Tsai, 2001. Magnetic and optical properties of $\mathrm{Fe}_{3} \mathrm{O}_{4}$ Nanoparticles ferofluids prepared by coprecipitation technique. IEEE Trans. Mag., 37: 2651-2653.
14. Massart, R., 1981. Preparation of aqueous magnetic liquids in alkaline and acidic media. IEEE Trans. Mag., 17: 1247-1248.

15. Goya, G.F., T.S. Berquo and F.C. Fonseca, 2003. Static and dynamic magnetic properties of spherical magnetite nanoparticles. J. Appl. Phys., 94: 3520-3528.

16. Lee, J.W., T. Isobe, T.M. Senna, 1996. Preparation of ultrafine $\mathrm{Fe}_{3} \mathrm{O}_{4}$ particles by precipitation in the presence of PVA at high $\mathrm{pH}$. J. Colloid Interface Sci., 177: 490-494.

17. Cao, Z., 2004. Nanostructures and Nanomaterials Synthesis, Properties and Applications, Imperial College Press, pp: 15-25. 